\title{
Pulmonary atresia with intact ventricular septum and corrected transposition of the great arteries
}

\author{
TATSUO SHIMIZU, MASAHIKO ANDO, ATSUYOSHI TAKAO \\ From the Department of Pediatric Cardiology, Heart Institute of fapan, Tokyo Women's \\ Medical College, Tokyo, fapan
}

SUMMARY We report an 82-day-old infant with a rare combination of anomalies: pulmonary atresia associated with corrected transposition of the great arteries and intact ventricular septum; this is the second such recorded case.

By using echocardiography, chest radiography, and electrocardiography the correct anatomical diagnosis was obtained before invasive investigation and necropsy.

An association of pulmonary valve atresia with intact ventricular septum and corrected transposition of the great arteries is a rare occurrence. We present a second such case following that reported by Steeg et al. ${ }^{1}$ in 1971 . In our case, non-invasive procedures, especially echocardiography, were diagnostic and were confirmed at necropsy as well as by angiography.

\section{Case report}

An 82-day-old Japanese female infant was admitted to the Heart Institute, Tokyo Women's Medical College, with a complaint of mild cyanosis since 4 days of age. She was the product of a 42 -week uneventful gestation except for mild toxaemia in a 32-year-old mother. The birthweight was $2940 \mathrm{~g}$. The presence of congenital heart disease was first confirmed at 57 days of age. However, the general condition including the respiratory status was described as good.

The physical examination disclosed a welldeveloped infant with slight generalised cyanosis, tachycardia, and tachypnoea. The liver was palpable $2 \mathrm{~cm}$ below the costal margin. The peripheral pulses were normal. The first heart sound was of normal intensity, the second heart sound was single and of increased intensity. A grade 1 ejection murmur and click were heard in the fourth intercostal space at the left sternal border.

The haematocrit was 51 per cent and the oxygen tension of capillary blood was $34 \mathrm{mmHg}$; the base excess was -8.3 and the carbon dioxide tension $34 \mathrm{mmHg}$.
The electrocardiogram (Fig. 1) showed sinus rhythm and a frontal plane mean QRS axis of +80 degrees with peaked $P$ waves in leads II, aVR, and aVF. The $Q$ wave in lead III was deep and the $R$ wave in lead V1 was $0.4 \mathrm{mV}$. A left ventricular dominant pattern was seen.

$$
\left(\frac{\mathrm{RV} 1+\mathrm{SV} 5}{\mathrm{SV} 1+\mathrm{RV} 5}<1 \cdot 0\right)
$$

$Q$ waves were absent in the left praecordial leads and lead aVL. Because of these findings ${ }^{2}$ corrected transposition was suspected.

The chest $x$-ray film showed situs solitus, a cardiothoracic ratio of 62 per cent, and severely decreased pulmonary vascularity. The left upper cardiac border was straight.

The echocardiogram (Fig. 2) disclosed a small atrioventricular valve on the right side, and a large atrioventricular valve was detected on the left side. Only one great artery (the aorta) was detected, and an infundibulum was interposed between the aorta and the large left-sided atrioventricular (tricuspid) valve.

At cardiac catheterisation both ventricles were entered, the left-sided systemic (anatomically right) ventricle was entered via an interatrial communication. Radiopaque contrast material injected into this left-sided ventricle filled the aorta arising antteriorly via an infundibulum along the left heart border. Pulmonary blood flow was supplied via a persistent ductus arteriosus; the main pulmonary artery was not filled. Right-sided (anatomically left) ventriculography showed a hypoplastic chamber with no direct communication to the great arteries or 


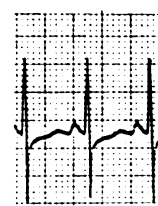

I

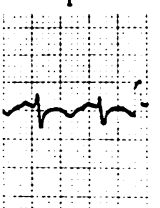

$V_{1}$

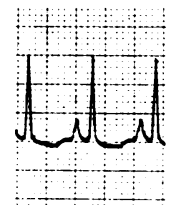

II

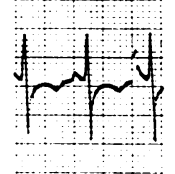

$v_{2}$

$2 M$

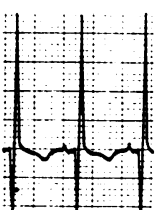

III

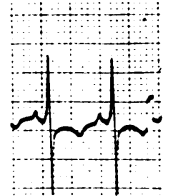

$V_{3}$

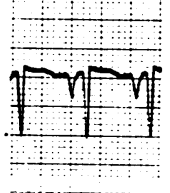

aVR

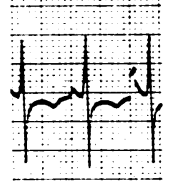

$V_{4}$

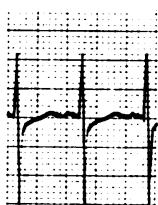

$\mathrm{aVL}$

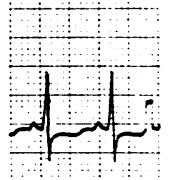

$V_{5}$

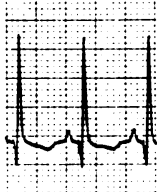

$\mathrm{aVF}$

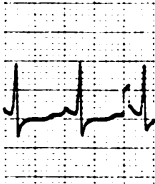

V6

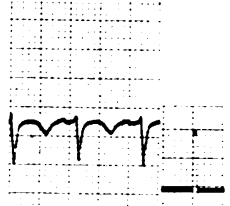

$\mathrm{V} 3 \mathrm{R}$

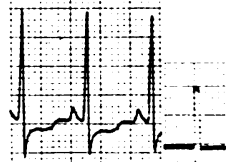

V7

$V_{1}-V_{6}$ Half standard

partly retouched

Fig. 1 Admission electrocardiogram. Sinus rhythm. Frontal plane axis $=+80$ degrees. Right atrial overloading pattern and hypoplastic right-sided ventricle can be seen. $Q$ waves are absent in leads $I$, aVL, and praecordial leads.

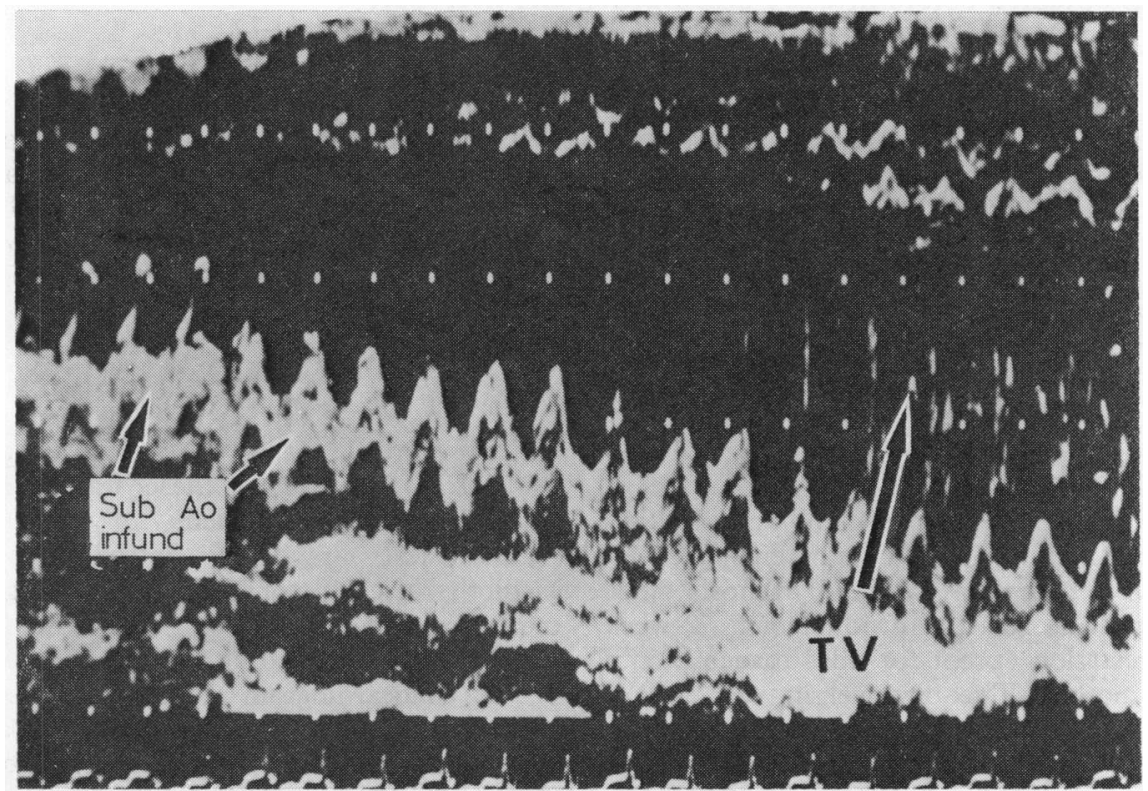

Fig. 2 Echocardiogram. A subaortic infundibulum intervenes between the aorta and the left-sided atrioventricular (anatomically tricuspid) valve.

to the other ventricle. Dilated myocardial sinusoids in the wall of this chamber were opacified.

From these findings, we made a diagnosis of either pulmonary atresia with intact ventricular septum and corrected transposition of the great arteries, or pulmonary atresia with intact ventricular septum and double outlet right ventricle with atrioventricular discordance.

After cardiac catheterisation, a right-sided subclavian artery-pulmonary artery anastomosis and atrioseptostomy were performed but the infant died on the first day after operation.

\section{PATHOLOGY}

The right-sided (anatomically left) ventricle was small; the left-sided (anatomically right) ventricle was large and occupied about four-fifths of the whole anterior aspect. There was a single left coronary artery. The aorta arose anteriorly via an infundibulum from the left-sided right ventricle. The main pulmonary artery was vestigial, located right posterior to the aorta, and was above the rightsided left ventricle. Fig. 3A shows the right atrium and right-sided left ventricle. The volume of this ventricle was peanut-size with hypertrophied 
myocardium, measuring $1.2 \mathrm{~cm}$ in thickness. There were fine trabeculations and a smooth septal surface in this chamber. The right-sided atrioventricular valve was a normal miniature of the mitral valve. No pulmonary outlet from this chamber was present and the ventricular septum was intact. The leftsided right ventricle had a large cavity and coarse trabeculation (Fig. 3B). The left-sided atrioventricular valve was tricuspid. The atrial septal defect produced by atrioseptostomy was visible at the interatrial septum. The right-sided subclavian artery-pulmonary artery anastomosis was also recognised. Thus the pathological diagnosis was pulmonary atresia with intact ventricular septum and corrected transposition of the great arteries.

\section{Discussion}

Corrected transposition of the great arteries seldom exists without associated cardiac malformations. ${ }^{1}$ The most common associated cardiac malformations are malpositions of the cardiac apex (isolated dextrocardia, mesocardia, and mirror image dextrocardia), ventricular septal defect, pulmonary stenosis, anomalies of the left atrioventricular valve (including regurgitation, stenosis, and atresia), and Ebstein's anomaly. ${ }^{3}{ }^{4}$ Pulmonary stenosis (or atresia) together with a ventricular septal defect is often seen in corrected transposition, ${ }^{5-7}$ but pulmonary stenosis with intact ventricular septum is rare in corrected transposition. ${ }^{5-7}$ Furthermore, pulmonary atresia with intact ventricular septum and corrected transposition of the great arteries is very rare, only one such case other than ours having been previously reported by Steeg et al. ${ }^{1}$

In our case, the clinical features were similar to those of pulmonary atresia with intact ventricular septum not associated with corrected transposition, and the differential diagnosis was at first clinically difficult. The reasons we suspected the correct diagnosis before cardiac catheterisation and angiography are as follows. (1) The electrocardiogram showed absence of $Q$ waves in leads $I, a V L$, and left praecordial leads, and there were $\operatorname{deep} Q$ waves in lead III. ${ }^{2}$ (2) On $x$-ray examination of the chest, the left upper cardiac border was straight. (3) The echocardiogram indicated absence of fibrous continuity between a left-sided atrioventricular valve (tricuspid valve) and the aortic valve (=presence of subaortic infundibulum). The correct anatomical diagnosis was verified by angiocardiography. Absence of $Q$ waves over the left praecordial leads in the electrocardiogram was noted in both our case and that reported by Steeg et al. ${ }^{1}$ The echocardiographic finding of the absence of fibrous continuity between the left-sided atrioventricular valve (tricuspid valve) and the aorta in our case was diagnostically helpful in establishing atrioventricular discordance. ${ }^{8}$

With meticulous application of non-invasive

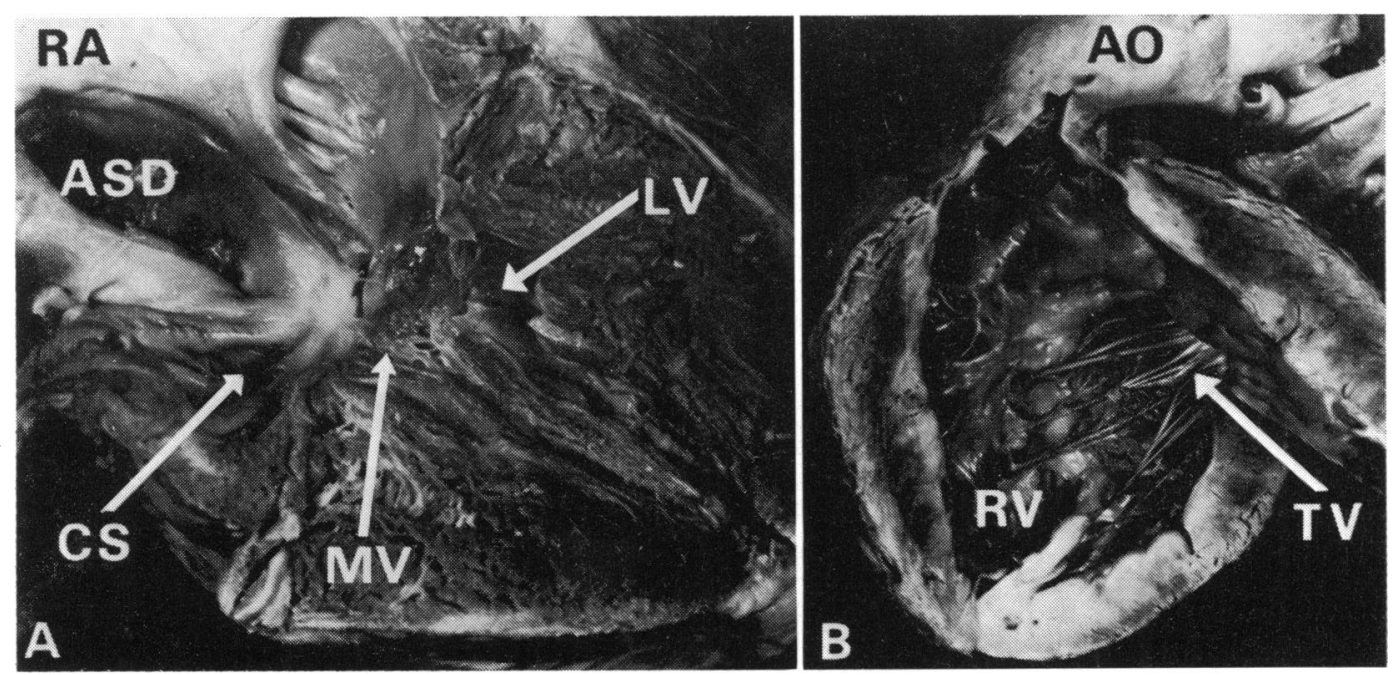

Fig. 3 (A) The right atrium (RA) and right-sided (anatomically left) ventricle (LV). The volume of this latter chamber is peanut-size with hypertrophied myocardium, measuring $1.2 \mathrm{~cm}$ in thickness. There is fine trabeculation of this chamber. The right-sided atrioventricular valve is a miniature of the normal mitral valve (MV). These findings indicate that this chamber is a left ventricle. No pulmonary outlet from this chamber is present and the ventricular septum is intact. ASD, atrial septal defect; CS, coronary sinus. (B) Left-sided right ventricle (RV). The cavity is large and the trabeculation is coarse. The aorta (AO) arises from this ventricle via an infundibulum. The left-sided atrioventricular valve is tricuspid (TV). These findings indicate that this chamber is a right ventricle. 
techniques, correct anatomical diagnosis can be obtained even in such rare conditions as our present case.

We are indebted to Dr A Kajita and Dr T Kanai of the Department of Pathology, Tokyo Women's Medical College, for showing us the necropsy specimen.

\section{References}

1 Steeg CN, Ellis K, Bransilver B, Gersony WN. Pulmonary atresia and intact ventricular septum complicating corrected transposition of the great vessels. Am Heart f 1971; 82: 382-6.

2 Okamura K, Takao A, Hashimoto A, Hosoda S, Mimori K. Electrocardiogram in corrected transposition of the great arteries with and without associated cardiac anomalies. F Electrocardiol 1973; 6: 3-10.

3 Ruttenberg HD. Chapter 20. In: Moss AJ, Adams FH, Emmanovilides GC, eds. Heart disease in infants, children and adolescents. 2nd ed. Baltimore: Williams \& Wilkins, 1977: 340.
4 Kidd BSL. Chapter 34. In: Keith JD, Rowe RD, Vlad $\mathrm{P}$, eds. Heart disease in infancy and childhood. 3rd ed. New York: Macmillan, 1978: 612-27.

5 Schiebler GL, Edwards JE, Burchell HB, DuShane JW, Ongley PA, Wood EH. Congenital corrected transposition of the great vessels: a study of 33 cases. Pediatrics 1961; 27: 851-88.

6 Anderson RC, Lillehei CW, Lester RG. Corrected transposition of the great vessels of the heart: a review of 17 cases. Pediatrics 1957; 20: 626-46.

7 Levy MJ, Lillehei CW, Elliott LP, Carey LS, Adams P Jr, Edwards JE. Accessory valvular tissue causing subpulmonary stenosis in corrected transposition of the great vessels. Circulation 1963; 27: 494-502.

8 Nagai Y, Atsuchi Y, Komatsu Y, et al. Echocardiographic findings in corrected transposition of the great arteries (in Japanese). Heart 1976; 8: 137-42.

Requests for reprints to Dr Tatsuo Shimizu, Department of Pediatric Cardiology, Heart Institute of Japan, Tokyo Women's Medical College, 10 Ichigaya-Kawada-cho, Shinjuku-ku, Tokyo 162, Japan. 